\title{
Expectativas sobre comportamiento egoísta ${ }^{1}$
}

\author{
Pablo Brañas-Garza \\ GLOBE: Universidad de Granada \\ María Paz Espinosa Alejos \\ Universidad del País Vasco \\ Teresa García-Muñoz \\ GLOBE: Universidad de Granada
}

\begin{abstract}
Resumen
En este trabajo presentamos los resultados de un experimento en el que se obtiene información sobre las creencias de los individuos referidas al peso que atribuyen al egoismo de los demás frente a la norma social que indicaría un comportamiento más generoso. La principal conclusión es que los individuos subestiman el egoísmo ajeno.

Keywords: juego del dictador, supuesto del egoísmo, expectativas.

Clasificación JEL: C91, D64, C72, H41.
\end{abstract}

\section{Abstract}

In this paper we present experimental results concerning the beliefs that subjects hold about the weight of selfishness on decision, compared to the social norm that would prescribe a more generous behavior. The main conclusion is that subjects underestimate selfishness.

Key words: dictator game, selfishness.

JEL classification: C91, D64, C72, H41.

\section{Motivación}

La Economía Experimental ha acumulado un conjunto de resultados relevantes, algunos de los cuales han constituido una contribución importante a cuestiones centrales en Economía. Con este trabajo pretendemos ilustrar cómo la Economía Experimental puede realizar aportaciones de interés para la modelización del comportamiento de los agentes económicos. En particular, exploramos el supuesto del egoísmo (o principio de maximización) que está en la base de gran parte de los modelos en Economía.

\footnotetext{
${ }^{1}$ Este proyecto nunca habría salido adelante sin Luis Miller, Fernan(do) Aguiar, Ramón (Cobo) y Natalia (Jiménez). El editor ha contribuido notablemente a mejorar el trabajo. También hemos de agradecer la generosidad de las instituciones: Espinosa agradece al MCI (SEJ2006-06309/ECON) y Gobierno Vasco, DEUI (IT-313-07); Brañas-Garza y García al MCI (SEJ2007-62081/ECON), a la Junta de Andalucía (P07-SEJ-02547) y al Instituto de la Mujer (2007 I+D+i/031).
} 
De manera más específica, el objetivo de este trabajo es estudiar si los agentes esperan que los demás individuos se comporten de acuerdo con el supuesto de maximización de su propio beneficio. Esta cuestión tiene interés porque los resultados de algunos modelos que utilizan el principio de maximización pueden no depender únicamente de que cada agente lo siga, sino también de que los agentes esperen que los demás lo sigan.

Para realizar esta investigación utilizamos un diseño muy sencillo y directo. Algo más de medio centenar de sujetos fueron informados de que recibirían la donación de un jugador en un Dictator Game (DG en adelante) ${ }^{2}$. Antes de abrir el sobre con la donación y, por tanto, saber la cantidad exacta de dinero que iban a ganar, se les ofreció dinero seguro a cambio de ese «dinero incierto». Esas ofertas se realizaron usando un mecanismo estándar de la economía experimental: las tarjetas de pago. Este mecanismo permite obtener una indicación de la valoración del sujeto, en este caso en qué medida valora la donación.

Bajo la hipótesis de que los sujetos maximizan su propio beneficio, la estrategia dominante para el dictador es no donar nada y por tanto la predicción del resultado que apuntaría el equilibrio de Nash es que la donación será cero. Por otro lado, si los receptores son conscientes de que los demás persiguen su propio beneficio, debemos esperar que los sujetos de nuestro experimento crean que sus oponentes jugarán de acuerdo con el equilibrio de Nash y por tanto, no donarán nada. Por consiguiente, los receptores deberían esperar encontrar los sobres vacíos y, por tanto, preferirán cualquier cantidad de dinero segura antes que la donación.

De los 53 receptores que nos dieron una valoración del comportamiento de los dictadores solo uno predijo que su rival se comportaría acorde con el equilibrio de Nash. Es decir, el 98,2\% de la población no considera el equilibrio de Nash de este juego, bajo el principio de maximización, como un buen predictor del comportamiento humano.

Utilizando este resultado como motivación, en este trabajo discutiremos la tensión existente entre un comportamiento normativo que favorecería un reparto igualitario y el principio de maximización del propio beneficio que implica decisiones egoistas. En primer lugar, en la Sección 2 se describe el juego del dictador y sus principales resultados. En la siguiente sección se describe el mecanismo a través del cual obtenemos información sobre las creencias de los individuos. La Sección 4 presenta los resultados y la Sección 5 concluye con una breve discusión.

\footnotetext{
${ }^{2}$ Como se verá en la Sección 2, el juego del dictador es un modo muy sencillo de analizar la generosidad a través de donaciones (entre dos jugadores). Uno de los jugadores (dictador) tiene la capacidad de repartir una cantidad fija de dinero entre él y otro jugador (receptor). El reparto propuesto por el dictador se lleva a cabo y el receptor no tiene ninguna capacidad de respuesta. Ver, entre otros, Andreoni y Miller [3], Andreoni y Veterlund [4], Bolton y otros [5] y Bohnet y Frey [6].
} 


\section{El juego del dictador}

Desde los años sesenta (en Eckel y Grossman [10] se puede encontrar una excelente revisión) el análisis de la cooperación y del comportamiento generoso se sistematizó a través del Dilema del Prisionero, estudiando diversas variaciones de las condiciones del juego. Sin embargo, en los años ochenta Guth y otros [14] introducen los experimentos del Juego del Ultimátum ${ }^{3}$, siendo una variante de éste, el Juego del Dictador, la que se ha impuesto para el análisis del altruismo.

En la versión original del Juego del Ultimátum (estático y para dos jugadores), el jugador número 1 (llamado proponente) ha de dividir una cantidad de dinero entre él y el jugador 2 (llamado receptor) en condiciones de total anonimato. A continuación, el jugador 2 acepta o rechaza la división. Si es aceptada, el reparto se hace conforme a la propuesta del jugador 1; si es rechazada ambos ganan cero.

El Juego del Dictador tiene esa misma estructura pero se elimina la posibilidad de decidir del jugador 2. Sea cual sea la división que lleve a cabo el jugador 1, el jugador 2 no tiene derecho a reclamar y el reparto será aquel que el jugador 1 decida (incluso siendo cero la cantidad destinada al receptor). Por ello, el jugador 1 toma el nombre de «dictador».

De manera genérica (ver en Hoffman, McCabe y Smith [15] una descripción amplia), el experimento se lleva a cabo de la siguiente manera: los sujetos experimentales son divididos en dos grupos y se colocan en dos aulas distintas: A (la de los dictadores) y B (la de los receptores). A cada dictador se le proporciona un sobre con 10 billetes de un dólar; en las instrucciones se indica que esa cantidad de dinero ha de ser asignada entre él y su compañero pero que es él quien tiene la capacidad de decidir la manera de repartirla, sea cual sea ésta. Tras las instrucciones el experimentalista se marcha y los sujetos llevan a cabo las asignaciones. Una vez tomada la decisión, dejan el sobre (con el dinero para el receptor) encima de la mesa (o en una urna) y se marchan. Los sujetos son conscientes de que no se guarda información alguna ni de la identidad ni de la acción de cada individuo.

Bajo una función de utilidad «convencional» la solución teórica del juego es simple: el dictador se queda con todo, el receptor no recibe nada. Sin embargo, en los múltiples experimentos realizados del DG se observan sistemáticamente valores distintos de cero para la cantidad asignada al jugador 2. Esto es, los dictadores no juegan acorde con las predicciones del principio de maximización.

Hoffman, McCabe y Smith [15] analizan ampliamente este resultado. Partiendo de la hipótesis de que las mismas instrucciones del DG no son nada neutrales (has de dividir una cantidad de dinero entre tu compañero y tú) proponen una serie de tratamientos alternativos que van sistemáticamente aislando al sujeto experimental (aumentando el anonimato) y generando así «distancia social». Distancia que hace que el sujeto se sienta más libre para llevar a cabo la acción que considere oportuna

\footnotetext{
${ }^{3}$ Ver el trabajo sobre el Juego del Ultimátum de García-Gallego, Georgantzis y Jaramillo en este mismo número.
} 
sin tener que soportar el coste de ser reconocido como egoísta. Como resultado, las transferencias de los dictadores en los experimentos con mayor grado de anonimato son cada vez más reducidas. Del trabajo se concluye que el incremento del aislamiento social (la imposibilidad de detectar el comportamiento egoísta) acerca a los sujetos a la solución teórica tradicional donde las contribuciones son cero.

En los últimos años han aparecido una serie de trabajos que condicionan parcialmente dichos resultados. Los nuevos diseños han incorporado información sobre el jugador $2 \mathrm{y}$, como consecuencia, han obtenido una disminución del número de sujetos que podríamos denominar completamente egoístas (donación=0) y un incremento espectacular en el porcentaje de individuos generosos con el receptor (donación 50\%). Ejemplos de estos tratamientos son Eckel y Grossman [11], donde el jugador 2 es la Cruz Roja de la localidad; Burnham [8], que proporciona fotografías de los receptores a los dictadores; Charness y Gneezy [9] que proporcionan a los dictadores los apellidos del receptor; Brañas-Garza [7], donde se les informa que los receptores son africanos y que recibirán el dinero en forma de medicinas y Frohlich y otros [13], donde los dictadores pueden ver a los receptores un momento antes del experimento.

En resumen, todos estos trabajos tratan de comprender porqué los sujetos se desvían sistemáticamente del equilibrio. La economía experimental ha aportado amplia evidencia de que en juegos con claras connotaciones sociales los agentes económicos se comportan de manera «generosa» con sus adversarios, incumpliendo el principio de maximización que nos dice que los individuos son racionales, esto es, maximizadores de su utilidad.

Esta aparente bondad de los individuos (o irracionalidad desde un punto de vista tradicional) se ha tratado de racionalizar bajo tres enfoques distintos:

- Altruismo: los individuos tienen en consideración lo que les pase a los demás y, por ello, están dispuestos a sacrificar ingresos para favorecerles. De una manera genérica podríamos decir que los individuos reciben utilidad por el mero hecho de transferir renta al otro.

- Reciprocidad: los individuos llevan a cabo sus acciones con intencionalidad y, por tanto, su aparente comportamiento inconsistente es perfectamente racional, si se tiene en cuenta que esperan algo a cambio de su generosidad. Sin embargo, en el DG convencional no hay lugar para las represalias ni para actuar de manera recíproca.

- Aversión a la Desigualdad: los individuos no sólo se preocupan de sus pagos (absolutos) sino también de los que pueda recibir otro individuo de la sociedad (relativos), esto es, se preocupan de la distribución (ver Fehr y Schmidt [12]) y están dispuestos a renunciar a parte de su pago para corregir la desigualdad. Con frecuencia es difícil diferenciar la aversión a la desigualdad de la justicia ya que, al relativizar los pagos los sujetos están dando un contenido moral a la distribución ${ }^{4}$.

\footnotetext{
${ }^{4}$ Un ejemplo típico donde los individuos anteponen sus criterios de justicia a la racionalidad son los juegos de ultimátum. Cuando el proponente hace una oferta «considerada» baja por el receptor éste
} 
De manera muy sintética y excluyendo argumentos tan prominentes como la identidad (ver Aguiar y otros [2] para una revisión) el DG muestra la tensión entre el comportamiento igualitario y el egoísta. Es decir entre la maximización de la utilidad del sujeto y el reparto igualitario.

El trabajo que aquí presentamos tiene un giro diferente a los anteriores ya que no queremos estudiar si la gente se comporta egoísta o igualitariamente sino si la gente espera que los otros se comporten de forma egoísta o de acuerdo a preferencias sociales [12]. Estas creencias sobre el comportamiento de los demás son un reflejo de la norma social que los individuos aplican a situaciones semejantes a las recreadas en el laboratorio.

\section{El experimento: mecanismo e implementación}

A través de pósters colocados en distintas facultades de la Universidad de Granada, obtuvimos respuesta de un centenar de sujetos. El día del experimento citamos a 75, de los que se presentaron 68. El experimento se realizó en dos sesiones (10 a.m. y 12 a.m.) sin posibilidad de comunicación entre ambas.

Los sujetos fueron informados de que se había realizado previamente un Juego del Dictador y que como resultado, las donaciones realizadas por los dictadores se encontraban disponibles en dos urnas idénticas (A y B). La primera tarea de los sujetos fue elegir de cuál de las dos urnas preferían obtener la donación ${ }^{5}$. Una vez tomada esta decisión, en la segunda tarea revelaron de forma indirecta sus creencias sobre la cantidad de dinero que dicha donación contenía.

Para obtener dicha información sobre las creencias se utilizó una tarjeta de pagos en la que el sujeto toma varias decisiones entre cantidades de dinero seguras y la donación. Estas decisiones proporcionan información sobre la cantidad que los individuos esperan obtener de la donación. La tarjeta de pagos era como la que se muestra en la Tabla 1.

\footnotetext{
reacciona rechazando la oferta y generando un beneficio igual a cero para ambos. En ese caso, los criterios de justicia (venganza) o la aversión (a ser mal-tratado) llevan al juego a una solución que no es compatible con la predicción del equilibrio de Nash perfecto en subjuegos. (ver Rabin [16]).

${ }^{5}$ Esta decisión, urna A o B, no afectó a lo que hicieron en la segunda fase $\left(Z_{M-W}=-1,23, p=0,22\right)$ En Aguiar y otros [1] el lector encontrará más detalles sobre el Juego del Dictador realizado previamente y que dio lugar a las donaciones.
} 


\section{FIGURA 1 \\ «TARJETA DE PAGOS»}

\begin{tabular}{c}
\hline 1. a decisión: donación ó $1 €$ seguro \\
\hline 2. a decisión: donación ó $2 €$ seguros \\
\hline 3. a decisión: donación ó $3 €$ seguros \\
\hline 4. a decisión: donación ó $4 €$ seguros \\
\hline 5. a decisión: donación ó $5 €$ seguros \\
\hline 6. a decisión: donación ó $6 €$ seguros \\
\hline 7. a decisión: donación ó $7 €$ seguros \\
\hline 8. a decisión: donación ó $8 €$ seguros \\
\hline 9. a decisión: donación ó $9 €$ seguros \\
\hline 10. a decisión: donación ó $10 €$ seguros \\
\hline
\end{tabular}

En la primera decisión, los sujetos eligen si prefieren 1 euro seguro o el dinero de la donación (todavía desconocido); en la segunda si prefieren la donación ó 2 euros, y así, sucesivamente. Deben señalar qué elegirían en las 10 decisiones. Sólo una de las decisiones, seleccionada al azar, será efectiva y el individuo recibirá la donación o la cantidad de dinero según lo que haya elegido en la tarjeta de pagos.

Los sujetos tienen una distribución de probabilidad subjetiva sobre distintos valores de la donación (que podría ser degenerada en un único valor). Imaginemos un agente neutral al riesgo. Si el sujeto considera que en el sobre hay una cantidad mayor (en media) que el dinero seguro, elegirá la donación mientras que preferirá el dinero seguro cuando considere que la donación es menor en valor esperado. Para un individuo averso al riesgo, su elección también nos proporciona información sobre sus creencias en cuanto a la donación, pero en este caso hay una prima de riesgo. El sujeto elegirá la donación si espera obtener algo más en valor esperado que la cantidad segura, para compensarle por el hecho de que la donación es incierta y entraña riesgo. Podría ocurrir que algún sujeto muestre un comportamiento amante del riesgo y prefiera la donación incierta con un cierto valor esperado a esa misma cantidad de dinero seguro. La curiosidad por saber qué hay en el sobre también 
podría inducir este tipo de comportamiento ${ }^{6}$, pero es cierto que esta curiosidad sobre el contenido de los sobres se podía satisfacer al final del experimento preguntando a los sujetos que hubiesen optado por la donación, por lo que es de esperar que el sesgo introducido no sea importante.

Un sujeto neutral al riesgo comenzará eligiendo la donación hasta que el dinero seguro sea mayor que su donación esperada. En ese momento "salta" de la columna donación a la columna de dinero seguro. Nosotros tomamos el lugar donde salta como el valor que el sujeto da a la donación, esto es, el sujeto que salta en la $3 .^{\text {a }}$ fila (elige donación en las 2 primeras filas y dinero seguro en la tercera) valora la donación entre 2 y 3 , de la misma manera que el que salta en la $6 .^{\text {a }}$ fila la valora entre 5 y 6 . En el caso de un individuo averso al riesgo la tarjeta de pagos nos permite calcular el equivalente cierto.

Antes de presentar los resultados en la sección siguiente, es útil hacer las siguientes consideraciones sobre el mecanismo de la tarjeta de pagos:

- hay evidencia contrastada de que no todos los individuos entienden bien una tarjeta de pagos. Aunque parece una manera natural de presentar la elección: juego vs. dinero, diferentes experimentos han mostrado que muchos sujetos se comportan de manera inconsistente cuando son enfrentados a este mecanismo ${ }^{7}$.

- hay mecanismos más directos para obtener creencias. Un mecanismo sencillo es preguntar a los sujetos, «¿cuánto dinero crees que hay en el sobre?». Estos mecanismos no son necesariamente mejores ya que el individuo no soporta ningún coste si no expresa sus verdaderas creencias.

De los 68 participantes de nuestro experimento, 15 de ellos mostraron alguna inconsistencia en sus decisiones en la tarjeta de pagos, esto es, saltaron más de una vez de columna, escogieron siempre la donación o comenzaron cogiendo dinero seguro y acabaron escogiendo la donación ${ }^{8}$. Las tarjetas de pagos de estos 15 participantes no fueron consideradas.

En la siguiente sección se muestran las predicciones de los 53 sujetos que completaron correctamente la tarjeta. De este mecanismo de elicitación obtenemos información sobre la cantidad de dinero que esperaban recibir en la donación, esto es, su predicción sobre el comportamiento (egoísta) de los dictadores.

\footnotetext{
${ }^{6}$ Agradecemos al editor este comentario sobre la curiosidad de los sujetos.

${ }^{7}$ Por ejemplo, un sujeto que salte más de una vez del lado izquierdo al derecho o bien no entiende el mecanismo o bien no es racional.

${ }^{8}$ Elegir siempre la donación es consistente con un comportamiento «amante del riesgo» o extremadamente «curioso», elegir una lotería que como máximo puede proporcionar 10 euros en lugar de aceptar 10 euros seguros; pero es más probable que indique una falta de comprensión por parte del individuo.
} 


\section{Resultados}

La Figura 1 ilustra el histograma de las predicciones de los 53 participantes ${ }^{9}$. De dicha figura se pueden resaltar cuatro ideas centrales:

- sólo un sujeto predijo el Equilibrio de Nash. Si aceptamos como próximas a cero cantidades de 2 euros o inferiores, podemos elevar el número de sujetos hasta 4 (ya que 2 predijeron una donación de 1 euro y 1 predijo una donación de 2 euros),

- 11 sujetos predijeron el reparto igualitario,

- 13 predijeron un comportamiento más generoso que el igualitario,

- 25 (algo menos de la mitad) predijeron un reparto no lejos del igualitario pero a la baja ${ }^{10}$.

Como se aprecia en la Figura 1, la distribución de predicciones que obtenemos parece estar centrada en valores intermedios, cercanos al reparto igualitario, y no es compatible con el equilibrio de Nash. Esto nos indica que los sujetos no esperan que los otros sujetos maximicen su utilidad, esto es, la racionalidad no es conocimiento común.

Una explicación sería que la norma social aplicable a situaciones similares a la generada en el laboratorio indique a los sujetos que las donaciones no estarán lejos de la igualitaria y por tanto eso es lo que esperan. Si esto es así, podríamos esperar que los resultados del Juego del Dictador no estén lejos del reparto igualitario. En la Figura 2 presentamos la distribución de donaciones ofrecidas por los sujetos en el Juego del Dictador. Comparando los resultados relativos a las creencias con la distribución de donaciones obtenida del Juego del Dictador, observamos que hay discrepancia. Hay un sesgo en las creencias. Los individuos esperan de los demás una mayor generosidad.

\footnotetext{
${ }^{9}$ La distribución fue como sigue (predicción y entre paréntesis el número de casos): 0(1), 1(2), 2(1), 3(13), 4(12), 5(11), 6(6), 7(6), 8(1), 9(0), 10(0).

10 Dar algo menos de la mitad es compatible con la idea de los derechos de propiedad. El dictador considera que tiene unos derechos adquiridos por ser jugador $1 \mathrm{y}$, por tanto, cobra una comisión. Ver Hoffman y otros [15].
} 
FIGURA 1

DISTRIBUCIÓN DE RESPUESTAS

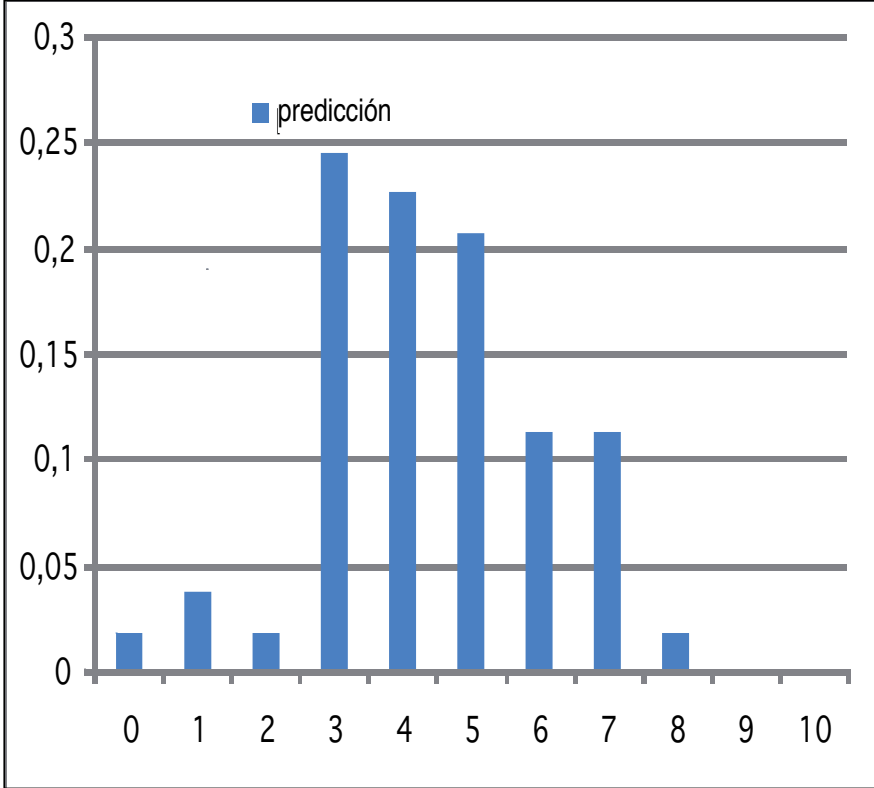

FIGURA 2

DISTRIBUCIÓN DE FRECUENCIAS

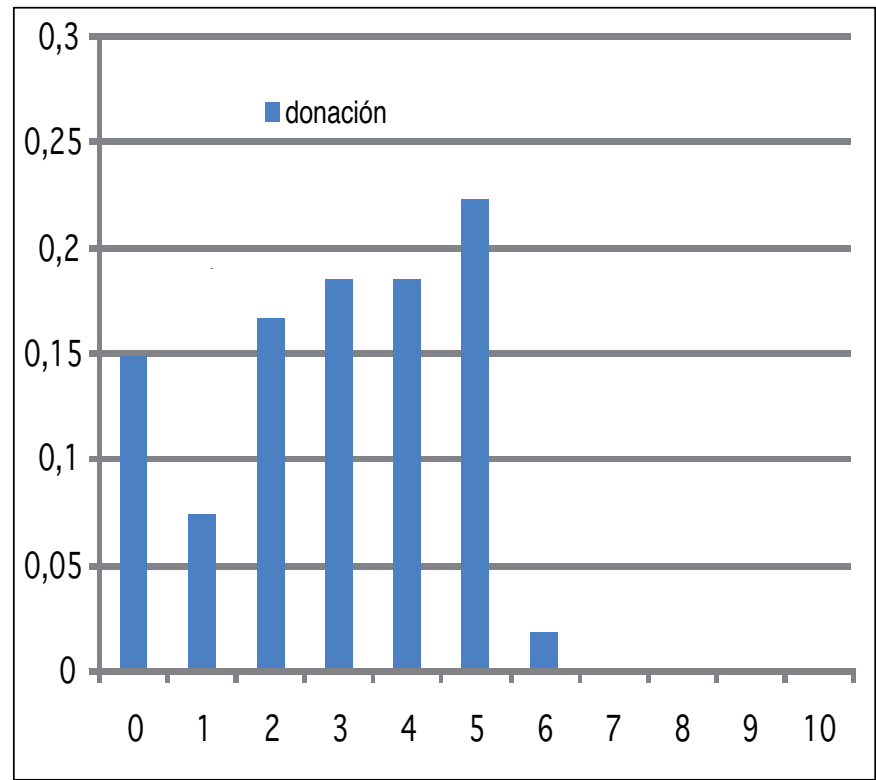




\section{Discusión}

El Juego del Dictador refleja de manera sintética la tensión que existe entre un comportamiento normativo que señala como apropiado un reparto igualitario y la tendencia a un comportamiento egoísta. Esta tensión se resuelve en valores intermedios entre el resultante del principio de maximización, una donación de cero, y el reparto igualitario (en nuestro caso se resolvió en una donación media en el Juego del Dictador de 2.9). Hay amplia evidencia de que la posición de este punto intermedio se ve afectada por las condiciones del experimento, muy en particular por el grado de anonimato en el que se realice, que afectan a la manera en que se resuelve el conflicto entre el comportamiento egoísta y la norma social aplicable a situaciones de asignación, es decir, entre la maximización de la utilidad del sujeto y el reparto igualitario.

Cuando los individuos tienen que predecir el resultado de esta tensión entre ambos principios, los resultados reflejan un sesgo hacia el reparto igualitario. Los participantes en el experimento revelaron que sus predicciones estaban más cerca de la norma social que del principio de maximización.

\section{Referencias}

[1] AGUIAR, FERNANDO, PABLO BRAÑAS-GARZA, RAMÓN COBO-REYES, NATALIA JIMÉNEZ y LUIS MILLER. Are women expected to be more generous?, Experimental Economics, 12 (1), pp. 93-98.

[2] AGUIAR, FERNANDO, PABLO BRAÑAS-GARZA, MARÍA PAZ ESPINOSA y LUIS MILLER (2008). Personal identity in the dictator game. Jena Economic Research Papers in Economics 2007-007

[3] ANDREONI, JAMES y JOHN MILLER (2002) Giving according to GARP: An experimental test of the consistency of preferences on altruism. Econometrica 70 (2), pp. 737-753.

[4] ANDREONI, JAMES y LISE VETERLUND (2001) Which is the bair sex? Gender differences in altruism. Quarterly Journal of Economics 116 (1), pp. 293-312.

[5] BOLTON, GARY, ELENA KATOK y RAMI ZWICK (1998). Dictator game giving: rules of fairness versus acts of kindness. International Journal of Game Theory, 27, pp. 269299.

[6] BOHNET I. y BRUNO FREY (1999). Social distance and other-regarding behaviour: Comment. American Economic Review, 89, pp. 335-340.

[7] BRAÑAS-GARZA, PABLO (2006). Poverty in dictator games: Awakening solidarity. Journal of Economic Behavior \& Organization, 60 (3), pp. 306-320.

[8] BURNHAM, TERENCE C. (2003). Engineering altruism: a theoretical and experimental investigation of anonymity and gift giving. Journal of Economic Behavior \& Organization, 50, pp. 133-144.

[9] CHARNESS, GARY y URI GNEEZY (2001). What's in a name? Anonymity and social distance in dictator and ultimatum games. Journal of Economist Behavior \& Organization, 68 (1), pp. 29-35. 
[10] ECKEL, CATHERINE y PHILIP GROSSMAN (1996). Altruism in anonymous dictator games. Games and Economic Behaviour, 16, pp. 181-191.

[11] ECKEL, CATHERINE y PHILIP GROSSMAN (1998). Are women less selfish than men? Evidence from dictator experiments. The Economic Journal, 108, pp. 726-736.

[12] FEHR, ERNST y KLAUS SCHMIDT (1999). A Theory of fairness, competition and cooperation. Quarterly Journal of Economics, 114, pp. 817-868.

[13] FROHLICH, NORMAN, JOE OPPENHEIMER y J. BERNARD MOORE (2001). Some doubts about measuring self-interest using dictator games: the cost of anonymity. Journal of Economic Behavior \& Organization, 46, pp. 271-250.

[14] GUTH, W., SCHMIFFBERGER, R y B SCHWARZE (1982). An experimental analysis of ultimatum bargaining. Journal of Economic Behavior \& Organization 3 (4), pp. 367-388.

[15] HOFFMAN, ELISABETH, MCCABE, KEVIN y VERNON SMITH (1996). Social distance and other-regarding behavior in dictator games. American Economic Review, 86 (3), pp. 653-660.

[16] RABIN, M. (1993). Incorporating fairness into game theory and economics. American Economic Review, 83 (5), pp. 1281-1303. 